\title{
The importance of medium specificity in writing and drawing
}

\author{
Francis Blore
}

\begin{abstract}
The intent of this essay is to consider the relationship between writing and drawing. The article will take a critical look at a set of propositions from the discourse on drawing which discuss the common ground shared by the two mediums. It will begin by considering how the modes were interlaced within Mel Bochner's 1966 Working Drawings and Other Visible Things on Paper Not Necessarily Meant to Be Viewed as Art, and then turn its attention to ideas from such figures as Hélène Cixous and Taro Amano. By addressing questions such as both mediums' allegiances in thought, form and the making of meaning, the hope is to suggest that within similarity there is still room for difference. The article will conclude by touching upon the work of Hanne Darboven to propose that the awareness of difference creates distinct ways to use both mediums to powerful effect.
\end{abstract}

Before the writing there is always thought. Here, thought flexed and folded over the ways in which the modalities of drawing and writing could share 3000 words. Through both recall and romance, what initially came to the fore was a set of coherences. Thought leaned into those moments where the connexion of 'hand, eye, mind' was not a circuitry, but a synchronicity. Moments, absent of time, where thinking was lithe, the hand lissom and line tumbled to the paper to remember the physical and speculative absorption of wonder. Thought turned to the sketchbook and its (typo) graphic recording of the kinetics of consciousness. Drawing and writing as un-precious attempts seeking precious ends.

Yet in the present tense, to make thought into an essay, to write about drawing, the coherences begin to slacken. Drawing becomes further distant and obstinate under attempts to transpose its recessitudes and withdrawals with each word written. Even the most liberal sentence denies more than it claims, as contingency is given assignation. There is the acute sense of 'not drawing' and as the words gather 'to write' can become to lose drawing (at least in part). The difference feels insistent and seems to beget the question of where do writing and drawing touch.

a. '[...] between the phases [...]' (Beckett quoted in Franke 2007: xii)

For the purposes of brevity, the thoughts of this essay are based in a contemporary, western under- standing of writing and drawing. From the point of view of drawing the impetuses and effects of Mel Bochner's 1966 exhibition Working Drawings and Other Visible Things on Paper Not Necessarily Meant to Be Viewed as Art prove a useful lead in to the modern purview. Through the device of displaying (or not displaying) Xeroxed copies of creative notabilia in stock black folders, the exhibition set out a critique of preceding adherences to the spectacular and irreducible essences of given mediums. The effect of this reductive presentation was a contraction of the visual insistence of art, which did not serve to elevate the preparatory, but rather pushed attention back to the private parlances of creation. As austere objects, these folders suggested the imperative of the beforehand, the idea as the active agent of art.

To this end, the contents of the folders were a set of somewhat dislocated trajectories, fallen from a process, that neither began nor end: punctums in the rash of thought. Sourced from an array of disciplines, the isolation and collection of what could be considered 'residue[s] of thought' (Bochner quoted in Stout 2014: 12) posited an interesting common thread. In an assemblage that reached from obscure open-ended text to forms seeking fabrication, and from hieroglyphic propositional formulae to apparent mappings of unknown spaces, the pages did not only oscillate between drawing and writing, they at times also cross-pollinated 
them. Through this blending, drawing and writing were identified as concurrent modalities in the act of seeking, handling and expressing the lability of thought. As such, the exhibition was couched as much in writing as it was drawing, unifying them through the compression of the objects and the attention to processes. Here, Bochner would affect a binding that affirmed the two mediums as having an ostensible proximity and indifference.

Possibly due to the difficulties inherent in discussing drawing directly, the binding under such an aegis has been a recurrent theme in drawing discourse. Notably, in 1991 Hélène Cixous wrote of drawing by relaying her thoughts back to her primary concern of writing. In the essay, a fluid inter- play is described between 'to write' and 'to draw', as Cixous considered these two acts to be 'twin adventures' (2005: 17). Through the text and emphasized by the title Without End [...] the comradery of the twin's adventure is located close to the notions of Bochner's speculative process. This is because in the reading, when writing is related to Cixous'ddrawingness' both can be thought of as acts of reconnaissance. The two modes come in to agreement as the access to, and agents within, a ceaseless field of potentiality: a place devoid of good and evil, where trial and error are simply facets of perpetual progression. The description of this liberal aesthetic rests in Cixous' use of groping, transient terms such as 'drunkness', 'darkness', 'seeking' and 'not finding' (2005: 17). Such terms can be seen as a device to illustrate the gaucherie of writing/drawing but, in being given a certain sensitivity they can also adhere the conceptual and physical processes. They seem to compel the tremor of anxious uncertainty and the fumbling embodiment of drawing/writing's lived condition.

Writing after Cixous in 2001, Taro Amano continued the discussion of drawing and writing's correlation. However, in taking on board both mediums' place in the process of live thought, Amano turns the focus more towards Bochner's object and the ideology of the fragment. Amano deploys Theodor W. Adorno's analysis of the essay as form to anchor a comparative reading of the drawn and the written. According to Amano, the drawing and the essay align because both are processual as they can act as 'a rough draft that polishes a concept' (Amano 2001: 164). The significance of this association is not the work's place in line but how the joint forgoing of completion allows the fragment to fragment internally. By giving weight to Adorono's proposition that 'the essay erects no scaffolding or structure' (Adorno quoted in Amano 2001: 165) the suggestion seems to be that the inherent liberty of the blank page becomes a container within which to kettle the volleying clatter and hum of thought. Here, drawing and writing become coupled as their incomplete, unpolished outputs can be viewed as a somewhat trembling errant assemblage that 'turns its eye towards something that changes easily and falls apart easily' (Amano 2001: 165). Moreover, for Amano it is the ability to fragment that makes the drawn/written such a pressing and poignant concern. For in recognition of a world of unfurling access and information that has lost its own completeness (ability to see the whole) the 'form that portrays fragments as fragments' (Amano 2001: 166) is essential. This is because the lability of their internal contingency is not just the tie that binds the structure of the drawn/written objects, it is the unison with which these objects speak and 'open up the possibilities of contemporary expression' (Amano 2001: 166).

B. '[...] in the flowers that cannot coexist [...]' (Beckett quoted in Franke 2007: xii) In these three interpretations, the modalities of writing and drawing are seemingly stitched and pulled taunt. Yet, should all these propositions be flipped inside out to reveal their seams rather than their cloth, a dividing line is arguably in play. For Bochner it can be read in the sometimes-lost caveat of 'and other visible things', for Cixous it is suggested in the duality and autonomy of 'twins', and for Amano it is in the operations of a comparative narrative. Irrespective of being perceived as slight or substantial, the dividing line is that which suggests there is (at least tacit) resistance to the wholesale fusion of writing and drawing through these arguments. What this points to is that, although comparable, the 
speculative agency and fragmented objects of writing do not constitute a mutable 'isness' with drawing.

One way of thinking towards 'isness' may be facilitated by shifting the frame of reference, as in Michel Butor's suggestion that: '[...] as soon as text enters the rectangle [...] one cannot help but notice that writing is drawing, writing is image' (Butor and Guynn 1994: 84). What seems to be proposed here is that by regarding the border as a pictorial frame, writing becomes a visual concern and allows one to seek out its drawn qualities. In looking for these qualities ease turns thought to the modal slippage of linear form, the sharing of the autobiographical hand and the necessity of space. Consider the repetitious ' $C$ ' that becomes a stormy ocean or the spherical ' $O$ ' that becomes the comic head and how just as quickly they could become constant and vowel. Notwithstanding the given intent, consider too that when produced by the hand such amorphous forms can be arrestingly imperfect in their wobbly inconsistency and kinesthetic registration. However, what is probably most significant in this shifting reference is the knotted line that can be left behind. A filament that illuminates negative space, insisting upon its purpose as void or light, break or pause. A line that regardless of being seascape or cursive exercise, drawing or writing, can construe a tangle so dense or loose that it will only lightly resist falling to the scribble.

Yet in this new frame of reference, all that seemingly pulls towards is arguably that which pushes apart and serves to offer writing independence. This is because the visual argument acknowledges that writing is not language per se but is the material representation of language. In an imaging of speech made perceptible the artist Joseph Grigely speaks of 'scraps of language lying on counter tops. Drawers full of sentences. Peeling of words in the sink' (Grigely quoted in Stout 2014: 105). Such imagery is evocative of more than writing's materiality; it also suggests a sense of its plasticity. It is this plasticity that allows writing to transpose from the compass scratched declaration of being there to the iridescent cut outs of birthday wishes to the in-memorandum inked on flesh. It is also that which allows one to think about how writing may be locally nuanced, of how: cadences can be frantic or solemn; gravity can be emboldened or diffused; bits and pieces can be stochastically strewn or decanted in to shape. In more prosaic terms, such thoughts also serve to reconstruct the current object of attention in as much as the plasticity of writing allows these words no, forms to recover their significance (presence) rather than their SIGNIFICATION. Therefore, it would seem feasible that what has been perceived as being bestowed by drawing is actually under the ownership of writing itself, and that writing's visual mutability is the operation of writing at play with itself.

Whereby writing reclaims its material plasticity, the independence it is offered begins to advocate a position for drawing and writing as two distinct mediums. As such, an adjunct concern is raised regarding what is meant by 'medium' and how do writing and drawings as mediums differ. In an article written in 2008, Jacques Rancière suggests that the first way medium is often understood is as 'that which holds between' and functions as the 'means to an end or the agent of an operation'(2011: 35). Having spoken of drawing and writing's betweenness and 'means to ends', such a definition seems useful as it will allow thought to continue on to agency and the operation of meaning.

In looking to claim meaning from either drawing or writing, the difference emerges through being confronted with contrary modes of locating information. In a video interview, Vija Celmins makes use of the word 'Bam!' (Tate 2014) to describe the reception of visual information, the brevity and impact of which is valuable here. Bam! expresses the quickness and force of drawing's initial sensual disclosure. It recalls the perceptual urgency of drawing that floods the visual with polysemic information, postponing or confusing the cognitive response. It is following this Bam! that drawing breaks down, dissolving in to the mutable significance of marks waiting to be filled with meaning. Here 'drawing hovers at the edge of recognition' (Cocker 2017: 108) compelling one to remain with the object and pour into its 
shifting meaning. This process of immediacy, dissolve and input can be seen to suggest meaning in drawing is both embedded and erratic.

Alternatively, in written information the dissolve becomes an accumulation towards meaning, which is more reliant on code and order. To read begins in cognition: there is recognition of process and form that implicates rehearsed patterns of travel and collection. Once gathered, due to their arbitrary nature, words will always point beyond themselves. This causes a departure from the object, an act of retuning words to a shared aural lexicon so they may constellate ostensibly and ephemerally according to their relationship rather than their condition. It is through this incremental gathering and departing that meaning is extracted and enticed to shine through the spaces between words. Unlike embedded presence, the deferral to a shared signification of mark implies that the written object "promotes its own oblivion' (Merleau-Ponty quoted in Morley 2007: 12) and the process of accumulative withdrawal becomes the delay before the Bam!

Curiously, it is by returning to the 'visual rectangle' frame of reference that the operative tension most prominently plays out. This is because where drawing and writing share the same rectangle they will often seek out a combined sense of meaning that the natural slippages or withdrawals of both image and word may not be able to account for alone. As such, regardless of whether they are intending to firm up or fissure each other, the two mediums use their difference as a generative friction. The rub comes from the required constitutional shift in trying to negotiate the perceptual and conceptual, the dissolve and accumulation, the here and there. It is by allowing drawing and writing to have these differences that a between space is created within which written and drawn information can be coerced. As more information is coerced it is the action of oscillating to-and-fro that causes the information to rub, melding and burnishing it to evolve the semblance of meaning. Although it can be initially jarring, the act can be as though one has to find the pace of the to-and- fro where the staccato gains rhythm. Such a motion is not simply a device employed where drawing and writing coexist, it is somewhat inevitable as attempting to attend to both synchronically would be to not to attend to either. This suggests it is in moments of visual proximity that drawing and writing's eking apart begins to take wider steps, for as Michel Foucault points out: '[t]he very thing that is to be seen and read is hushed in vision, hidden in the reading' (1983: 24).

c. '[...] of unspeakable territory' (Beckett quoted in Franke 2007: xii) Having found some difference between writing and drawing, the desire here is not to be precious about it, but to think around how to make use of it. This very possibility comes from noting that so far both writing and drawing have stayed intact. The importance of difference here is that it allows one to perceive the edges of a medium and to interrogate their ostensible construction. It is knowing difference that facilitates the purposeful rupture of the edges so that certain conditions are lost and gained with meaningful intent.

The work of Hanne Darboven is one such example of how the perception and manipulation of the medium's edges can be used in a captivating way. For Darboven, her practice involved writing, but at the same time it can be seen to resist writing. In much of her work devices such as a 'uuuuuu' wave script became a way to write without describing so as to jettison reading and the departure to meaning. In this rolling cursive, the gestures appear meaningful yet mute. To read 'uuuuuu' is to bob upon a silent cadence and to immerse into the somatic and sensual rhythm of the marks. The resistance can also be found in the display of work: panels floor to ceiling, wall to wall. Unable to clearly engage the summit the fixed entry is denied and panel on mass distresses order, scattering the narrative. In this way, Darboven's 'writing fills the space that drawing would' (Chaffee 2013: 14), yet this space can also be seen as being resisted. Instinctively the script bears all the hallmarks of writing: regularity, order, repetition, system, control, diligence and uniformity. In doing so, the work 'stage[s] the experience of reading' (Chaffee 2013: 14) to defer drawing. Each panel 
designs (yet obfuscates) the way through, firing the departure to meaning (albeit to darkness). When reminded to remain present, the 'staging' within the vast display begins to return a written aural quality to the work. The multiplicity and breadth of panels can overwhelm and cocoon, imposing the sense of being internalized within a process, of being brought in to the fizz and pop of another's thought. Once there, the imposing display keys in to the anticipation of reading, triggering the works to speak at once, cascading over each other in to a polyphonic flood. Such nuances in Darboven's resistances are arguably an act of handling the medium's edges with care. In letting neither writing nor drawing incur or retreat too far from the border there is controlled loss/gain: the written is hushed/presented, the drawn hidden/loudened. Moreover, in some way, by not wholly committing to either medium, Darboven's work becomes neither yet both.

What this brief positioning hopefully brings in to view is the importance of medium specificity. This reason for wanting to unpick the similarities and differences between writing and drawing, was not to advocate a need for purity, but rather to suggest that the awareness of how things separate is valuable. Wherein there is a certain contemporary insistence placed upon fluidity and mutability, it can seem at times that the speed and growth of the "expanded field' can smooth over the cracks that bring detail and texture to the broad wash. For as Anita Taylor suggests: the danger might be that one is left with a clear impression that drawing can be everything. This has the constituent problem that if drawing is everything, then it also nothing - or at least nothing special. (2012: 11)

By allowing difference to become part of the conversation there is recall to those wonderful acts of dissonance. In this article, thinking about medium specificity is suggested as a way for writers, drawers and writer-drawers to press with force against the edges of medium. To pierce the edges of the medium so that its conditions may (con)fuse in those unspeakable territories, and to create opportunity to fill the reader-seer with the brilliant anxiety of not knowing and trying to find a way to respond.

\section{References}

Amano, T. (2001), 'Towards fragmentation: Drawing as form', in Yoshimoto Nara: I Don't Mind if You Forget Me, exhibition catalogue, Yokohama Museum of Art, Yokohama, 11 August - 14 October, pp. 161-167.

Butor, M. and Guynn, N. (1994), 'Bricolage: An interview with Michel Butor', Yale French Studies, 84, pp. 17-26, http://www.jstor.org/stable/2930177. Accessed 19 July 2012.

Chaffee, C. (2013), Abstract Corresponance, New York: Castelli Gallery, https://www.castelligal- lery.com/images/publications/publications_PDF/Darbovenweb.pdf. Accessed 1 November 2017.

Cixous, H. (2005), 'Without end, no, state of drawingness, no, rather: The executioners taking off', in Stigmata: Escaping Texts (trans. Catherine A. F. MacGillivray), London: Routledge. pp. 16-27.

Cocker, E. (2017), 'Distancing the if and then', in N. Gansterer (ed.), Drawing a Hypothesis: Figures of Thought, 2nd ed., Berlin and Boston: Walter de Gruyter GmbH, pp. 97-108.

Foucault, M. (1983), This is Not a Pipe, Berkeley: University of California Press.

Franke, W. (2007), On What Cannot be Said, Notre Dame, IN: University of Notre Dame. Morley, S. (2007), Writing on the Wall, London: Thames \& Hudson. 
Rancière, J. (2011), 'What medium can mean'(trans. Steven Corcoran), Parrhesia, 11, pp. 35-43, http:// www.parrhesiajournal.org/parrhesia11/parrhesia11_ranciere.pdf. Accessed 26 September 2017.

Stout, K. (2014), Contemporary Drawing, London: Tate Publishing.

Tate (2014), 'Vija Celmins - Artist Rooms|Tateshots', 14 April,

https://www.youtube.com/watch? v=SsbkzSrCdlg. Accessed 1 November 2017.

Taylor, A. (2012), 'Foreword - Re-positioning drawing', in S. Garner (ed.), Writing on Drawing: Essays on Drawing Practice and Research, Bristol: Intellect, pp. 9-11. 